\title{
GAYA KOMUNIKASI AHOK BERDASARKAN PERSPEKTIF KOMUNIKASI LINTAS BUDAYA
}

\author{
Aprilyanti Pratiwi \\ aprilyantipratiwi@univpancasila.ac.id \\ Universitas Pancasila
}

\begin{abstract}
2019 is the year of Ahok's return after serving a prison sentence of 2 years. It is still embedded in people's memories of how the character of Ahok as a leader is very different from the character of leaders in Indonesia. The purpose of this study is to analyze Ahok's communication style while serving as the Governor of DKI Jakarta in terms of the context of cross-cultural communication. The method used in this study is qualitative by analyzing online news that displays Ahok's communication style. In addition, this study also uses literature studies in the form of previous research literature that examines Ahok's communication style. The results showed that based on cross-cultural perspectives, Ahok as an official and or political elite used Low Context Culture (LCC) communication style. Ahok displays a communication style that is outspoken or to the point. He paid little attention to the value system. If he considers that other people wrong, then he does not hesitate to say it without caring what he expressed is contrary to the values adopted by the people of Indonesia. However, there are several Ahok communication styles that do not conform to the characteristics of the LCC, namely when speaking Ahok tends to use non-formal language with high voice intonation.
\end{abstract}

\section{Keywords: Communication Style, DKI Jakarta Governor, Ahok, Cross Culture Communication, Low Context Culture}

\begin{abstract}
ABSTRAK
Tahun 2019 menjadi tahun kembalinya Ahok setelah menjalani hukuman penjara selama 2 tahun. Masih lekat dalam ingatan masyarakat bagaimana karakter Ahok sebagai pemimpin sangat berebeda jauh dengan karakter pemimpin di Indonesia. Tujuan penelitian ini adalah untuk menganalisis gaya komunikasi Ahok pada saat menjabat sebagai Gubernur DKI Jakarta ditinjau dari konteks komunikasi lintas budaya. Metode yang digunakan pada penelitian ini adalah kualitatif dengan menganalisis pemberitaan online yang menampilkan gaya komunikasi Ahok. Selain itu penelitian ini juga menggunakan studi kepustakaan berupa literatur penelitian terdahulu yang mengkaji mengenai gaya komunikasi Ahok. Hasil penelitian menunjukkan bahwa berdasarkan perspektif lintas budaya, Ahok sebagai seorang pejabat dan atau elit politik menggunakan gaya komunikasi Low Context Culture (LCC) atau komunikasi konteks rendah. Ahok menampilkan gaya komunikasi yang blak-blakan atau to the point dan tidak suka bertele-tele. Ia kurang memperhatikan sistem nilai. Apabila ia menganggap orang lain salah, maka ia tak segan-segan
\end{abstract}


mengatakannya tanpa perduli yang diungkapkannya tersebut bertolak belakang dengan nilai-nilai yang dianut masyarakat Indonesia. Namun terdapat beberapa gaya komunikasi Ahok yang tidak berkesesuaian dengan karakteristik LCC, yaitu ketika berbicara Ahok cenderung menggunakan bahasa non formal dengan intonasi suara yang tinggi.

\section{Kata kunci: Gaya Komunikasi, Gubernur DKI Jakarta, Ahok, Komunikasi Lintas Budaya, Komunikasi Konteks Rendah}

\section{PENDAHULUAN}

\begin{tabular}{llll}
\multicolumn{2}{c}{ Kita dapat memenuhi } \\
kebutuhan hidup kita & jika kita \\
berkomunikasi dengan orang lain
\end{tabular}
(Liliweri, 2007). Melalui kalimat tersebut dapat dikatakan bahwa begitu pentingnya komunikasi yang dilakukan seseorang dengan orang lain sehingga mampu memenuhi kebutuhan hidupnya. Lebih lanjut Porter et.al (1996) menjelaskan bahwa komunikasi menjadi sempurna jika orang lain (komunikan) memiliki pemaknaan dan persepsi yang sama atas pesan yang kita sampaikan.

Bagai koin mata uang yang memiliki dua sisi, komunikasi dan budaya memiliki hubungan sangat erat dan tak terpisahkan. Satu sisi, budaya merupakan penggalan dari perilaku komunikasi seseorang. Namun di lain sisi, komunikasi mampu membentuk budaya, memeliharanya, mengembangkannya dan mewariskannya. Dengan demikian dapat dinyatakan bahwa budaya seseorang dapat mempengaruhi cara orang tersebut dalam berkomunikasi. Peserta komunikasi yang datang dari budaya yang berbeda tentunya memiliki tata cara komunikasi yang juga berbeda. Oleh karena itulah sering kali terjadi misunderstanding yang dialami peserta komunikasi yang memiliki budaya yang berbeda (Mulyana, 1996).

Cukup unik jika kita memperhatikan bagaimana seorang politisi dari satu budaya tertentu berkomunikasi dengan audiensnya yang berasal dari budaya lain. Bagaimana cara ia membentuk citra positif di tengah-tengah perbedaan yang mereka miliki? Ada banyak gaya komunikasi yang diterapkan oleh pemimpin untuk meraih simpati rakyat. Berbagai strategi komunikasi politik dilakukan setiap pejabat atau elit politik untuk meningkatkan citra positif dibenak masyarakat. Setiap pemimpin berusaha membangun citra positif dengan menampilkan gaya komunikasi yang santun dan bersahaja. Namun tidak demikian dengan Ahok. Saeni (2017) menjelaskan bahwa ia memiliki gaya komunikasi yang dianggap jauh dari ideal. Ahok dianggap sebagai seorang pemimpin yang kontroversial dengan banyak melakukan kejutankejutan, baik pada kebijakan-kebijakan yang ia buat maupun keputusan politiknya.

Diantara pejabat politik dan elit politik Indonesia, nama Ahok menjadi 
fenomenal. Sebagai seorang Gubernur, Ahok memiliki track record tersendiri di mata rakyat DKI Jakarta. Pada 2015 lalu, Periskop Data melakukan survei mengenai kepuasan publik terhadap kepemerintahan Ahok sebagai Gubernur DKI Jakarta. Reseponden pada survei ini sebanyak 500 orang. Reseponden dipilih dengan acak dengan kriteria berumur lebih dari 17 tahun atau telah menikah. Survei dilaksanakan di enam kabupaten/kota di Jakarta dan dilaksanakan dari tanggal 1 Juni hingga 7 Juni 2015. Salah satu indikator dalam survey tersebut adalah mengenai gaya komunikasi Ahok. Hasil survei tersebut menunjukkan $\quad 70,4 \%$ responden menyatakan bahwa Ahok tidak memiliki sopan santun sebagai kepala daerah. $77 \%$ responden menginginkan agar Ahok membenahi cara berkomunikasinya. Dengan demikian berdasarkan survei tersebut gaya komunikasi Ahok tidak berkenan di hati masyarakat karena dianggap kasar, arogan, kurang ramah dan cenderung emosional.

Menarik untuk mengkaji gaya komunikasi yang ditampilkan Ahok sebagai seorang kepala daerah sebagaimana yang diungkapkan Muksin (2017) bahwa gaya komunikasi seorang pemimpin merupakan suatu yang urgen berkaitan dengan kebijakan-kebijakan yang diambilnya. Terdapat beberapa penelitian sebelumnya yang membahas mengenai gaya komunikasi Ahok. Diantaranya adalah penelitian yang dilakukan oleh Prasetyo (2014) yang berjudul "Persepsi Masyarakat DKI Jakarta Terhadap Figur dan Komunikasi Politik Basuki Tjahaja Purnama". Penelitian ini ingin mengetahui bagaimana persepsi masyarakat khususnya masyarakat DKI Jakarta terhadap figur Ahok dan bagaimana komunikasi politik yang telah dijalankannya selama menjabat sebagai Wakil Gubernur DKI Jakarta. Penelitian selanjutnya yang juga mengkaji mengenai gaya komunikasi Ahok, yaitu penelitian yang dilakukan oleh Wijayanti et.al (2014) dengan judul Retorika dan Gaya Kepemimpinan Ahok dalam Penegakan Kebijakan di Jakarta. Penelitian tersebut bertujuan untuk menganalisis retorika dan gaya kepemimpinan Ahok dalam melakukan penegakan kebijakan di Jakarta.

Rani (2014) juga melakukan penelitian mengenai Ahok dengan judul "Preferensi Opini Publik dalam Media Online (Preferensi Opini Publik terhadap Citra Ahok dalam Lipsus Kompas.com tentang Penertiban PKL Pasar Tanah Abang Bulan Juli 2013)”. Tujuan penelitian tersebut adalah untuk mengetahui opini publik terhadap citra Ahok pada Kompas.com. Penelitian lain yang juga mengkaji mengenai gaya komunikasi Ahok adalah penelitian yang dilakukan oleh Muksin (2017) dengan judul "Kredibiltas Komunikator Politik Basuki Tjahaya Purnama "Ahok" Sebagai Gubernur 
Provinsi DKI Jakarta". Tujuan penelitian tersebut adalah untuk menggambarkan gaya komunikasi politik Ahok baik secara verbal maupun non verbal. Tujuan lainnya, yaitu untuk menganalisis etika komunikasi politik yang dimiliki Ahok. Selain itu, tujuan selanjutnya adalah untuk menjelaskan kredibilitas yang dimiliki Ahok sebagai seorang komunikator politik.

Penelitian selanjutnya yang juga meneliti gaya komunikasi Ahok berjudul "Gaya Komunikasi Pemimpin Di Media (Analisis Semiotika Gaya Komunikasi Basuki Tajahaja Purnama "Ahok" Dalam Tayangan Mata Najwa On Stage "Semua Karena Ahok" Di Metro TV)" yang ditulis oleh Rahmah (2018). Tujuan penelitian tersebut untuk menemukan makna denotasi, konotasi dan mitos yang terdapat pada gaya komunikasi Ahok. Fokus penelitian tersebut adalah analisis semiotika gaya komunikasi pemimpin di media.

Berdasarkan pada penjabaran terhadap kajian penelitian terdahulu di atas, dapat diketahui bahwa belum ditemukannya penelitian mengenai gaya komunikasi Ahok dengan menggunakan pendekatan komunikasi lintas budaya. Oleh sebab itu maka penelitian ini akan mengkaji gaya komunikasi Ahok dengan pendekatan komunikasi lintas budaya.

\section{METODE PENELITIAN}

Metode pada penelitian ini adalah kualitatif. Penelitian ini menggambarkan gaya komunikasi Ahok (Basuki Tjahaja Purnama) selama menjabat sebagai Gubernur DKI Jakarta. Pada penelitian ini data yang dipergunakan adalah sumber tertulis, yaitu beberapa pemberitaan mengenai Ahok (Basuki Tjahaja Purnama) selama menjabat sebagai Gubernur DKI Jakarta. Selain itu penelitian ini juga menggunakan metode studi kepustakaan yaitu melalui literatur penelitian terdahulu yang mengkaji mengenai gaya komunikasi Ahok.

\section{HASIL DAN PENELITIAN}

Basuki Tjahaja Purnama atau lebih akrab disapa Ahok merupakan Gubernur DKI Jakarta yang menjabat sebagai Gubernur DKI Jakarta sejak 19 November 2004. Sebelumnya Ahok menjabat sebagai Wakil Gubernur dan Plt atau Pelaksana tugas Gubernur yang sebelumnya dijabat oleh Jokowi. Selama menjabat sebagai Gubernur DKI Jakarta, gaya kepemimpinan Ahok memang telah menarik perhatian berbagai kalangan. Tidak hanya warga DKI Jakarta saja yang mengenal karakter Ahok yang keras, namun warga dari daerah lain pun mengetahui bagaimana karakter seorang Ahok. Berita mengenai gaya kepemimpinan Ahok yang meledak-ledak dan kontroversial kerap kali menghiasi layar kaca nasional, diantaranya adalah pemberitaan mengenai waduk Pluit dan 
penertiban PKL di pasar Tanah Abang. Sebagai seorang komunikator politik apa yang ditampilkan Ahok di televisi menuai berbagai pendapat, baik yang positif maupun negatif.

Ahok cenderung memisahkan isu dan orang yang mengkomunikasikan isu. Walaupun Ahok pada awalnya bersikap emosional terhadap wartawan yang akan mewawancarainya, yaitu memarahi dan mengusir wartawan tersebut, akan tetapi Ahok pada akhirnya mempersilahkan wartawan tersebut untuk mewawancarainya pada keesokan harinya. Dikutip dari Kompas.com edisi 17 Juni 2016, diketahui bahwa pada 16 Juni 2016 Ahok memarahi dan menunjuk wartawan sebuah media online. Ahok pun tidak memperbolehkan wartawan tersebut untuk melakukan liputan di Balai Kota. Perlakuan yang dilakukan oleh Ahok ini bukanlah tanpa sebab. Ahok berang atas pertanyaan yang dilontarkan oleh wartawan tersebut yang menanyakan mengenai selentingan mengenai aliran dana sebesar Rp. 30 miliar yang diterima oleh "Teman Ahok" sebagai kelompok relawan Ahok dari pengembang reklamasi.

Ahok merupakan tipikal pejabat yang temperampental. Setidaknya pernyataan tersebut disampaikan oleh Yusril Ihza Mahendra seperti dikutip Kompas.com edisi 17/06/2016. Ahok juga merupakan pribadi yang tidak suka basa-basi dan cenderung lugas dalam berkomunikasi. Sifatnya yang tidak suka basa-basi dan lugas inilah yang membuatnya seringkali dinilai orang lain sebagai seseorang yang emosional. Padahal sifat Ahok yang emosional itu merupakan ekpresi yang ia keluarkan atas situasi yang ia alami sebagai seorang yang tidak suka berbasa-basi.

Ahok juga mengutamakan informasi secara verbal, walaupun kemudian diikuti oleh nonverbalnya. Perlakuan Ahok yang memarahi dan mengusir wartawan merupakan komunikasi yang dilakukan Ahok secara verbal, yaitu komunikasi yang diucapkan dengan lisan. Berbarengan dengan komunikasi yang ia sampaikan secara lisan tersebut, Ahok pun menampilkan komunikasi nonverbal, yaitu dengan vokal dan intonasi suara yang tinggi. Muksin menyatakan bahwa gaya komunikasi Ahok dengan vokal dan intonasi suara yang tinggi ini merupakan gaya komunikasi yang meledak-ledak. Gaya komunikasi yang meledak-ledak serta intonasi suara yang tinggi ini dianggap tidak ramah dan tidak menyenangkan oleh sebagian masyarakat kita, terlebih masyarakat Jawa dan Sunda yang memiliki tutur kata dan intonasi yang cenderung lemah lembut. Masih menurut Muksin (2017), gaya komunikasi Ahok yang meledak-ledak tersebut merupakan ekspresi kemarahan. Ekspresi kemarahan dianggap masyarakat kurang etis jika ditampilkan oleh seorang pemimpin. 
Masyarakat menganggap seorang pemimpin idealnya memiliki sikap mengayomi, sabar dan menjadi pendengar yang baik. Gaya komunikasi yang ditampilkan Ahok yang memiliki intonasi tinggi tersebut juga dianggap tidak mencerminkan sosok pemimpin yang bijaksana. Masyarakat menilai bahwa seorang pemimpin wajib menjadi contoh yang baik bagi bawahannya dan masyarakat luas.

Hasil kajian yang kurang lebih senada juga ditemukan oleh Saeni (2017). Secara garis besar diketahui bahwa Ahok memiliki gaya komunikasi yang tak biasa jika dibandingkan dengan pejabat Indonesia lainnya. Ahok lebih menyukai berbicara dengan menggunakan nada yang tinggi dibarengi dengan mata melotot dan telunjuk yang menuding. Sangat bertolak belakang dengan gaya komunikasi yang dimiliki oleh pejabat Indonesia lainnya yang cenderung berbicara lembut serta santun yang dibarengi gesture tubuh yang ditata.

Saeni (2017) menemukan bahwa Ahok seringkali memilih katakata yang anti-mainstream dari penggunaan bahasa yang ditampilkan pejabat Indonesia umunya. Ahok memilih kata-kata gaul khas anak muda jaman sekarang seperti "emang gua pikirin", "tanah nenek moyang lu" atau "gue ngga mau tau". Pada saat ditanya jurnalis pada saat wawancara pun, Ahok dengan santainya menjawab dengan menggunakan bahasa non- formal seperti: "lu" dan "gue". Hasil kajian tersebut juga menemukan bahwa Ahok seringkali melontarkan kata-kata kasar seperti "akan gue sikat", "bego", dan "hajar saja".

Salah satu masalah yang menjegal Ahok pada masa kampanyenya adalah kasus penistaan agama. Masyarakat muslim Indonesia menganggap pernyataan Ahok mengenai interpretasinya atas surat AlMaidah adalah keliru besar dan merupakan suatu penistaan agama. Padahal Ahok tidak bermaksud demikian. Seperti kita ketahui bersama bahwa Ahok terjerat kasus penistaan agama hingga Ahok harus mendekam di penjara. Kasusnya berawal 27 September 2016, ketika Ahok melaksanakan kunjungan kerja ke Kepulauan Seribu, Jakarta. Pada kunjungan kerjanya tersebut, Ahok mengadakan dialog dengan warga setempat dan juga menebar ribuan benih ikan. Pada pidato sambutannya, Ahok menghimbau agar warga tidak khawatir dengan kebijakan yang telah dibuat pada masa kepemerintahannya. Ahok pada pidatonya tersebut menambahkan bahwa jika nanti ia tidak terpilih menjadi Gubernur DKI, program pemerintah yang telah ia rancang di Kepulauan Seribu tersebut akan tetap berjalan. Pada pidatonya itu, Ahok menyampaikan dengan gaya yang santai dan lugas. Di sela-sela pidatonya ia menyisipkan Surat Al Maidah ayat 51. Tak disangka pidato Ahok tersebut banyak diperbincangkan 
di dunia maya, utamanya kalimat mengenai Surat Al Maidah ayat 51 .

Jika kita telaah dengan seksama video yang mana Ahok dianggap melakukan penistaan agama tersebut, Kalimat Ahok yang berbunyi: "...dibohongin pake surat Al Maidah ayat 51..." memiliki maksud bahwa Ahok merujuk pada individu atau kelompok tertentu yang menggunakan surat Al-Maidah atas dasar kepentingan politik untuk membohongi masyarakat agar tidak memilihnya sebagai Gubernur pada Pemilihan Gubernur DKI 2017. Jadi jelas bahwa kata "dibohongi" merujuk pada "orang", bukan pada "Al-Quran Surat Al Maidah Ayat 51".

Pada 2015 lalu, Kompas melakukan survey terhadap karakter Gubernur DKI Jakarta. Sebagaimana dikutip dari Kompas.com edisi 27/05/2015 diketahui bahwa Ahok memiliki nilai tertinggi pada kejujurannya. Sebanyak 7,53 responden mengakui kejujuran Ahok. Ketegasan dan keberanian Ahok juga menjadi keunggulannya. Masyarakat juga memberikan apresiasi kepada kemampuan Ahok dalam memimpin kepala dinas DKI Jakarta. Kesederhanaannya pun menjadi keunggulan yang dimiliki Ahok jika dibandingkan dengan Gubernur DKI Jakarta lainnya. Berdasarkan poin-poin tersebut dapat dikatakan bahwa masyarakat tidak tetrlalu mempermasalahkan gaya komunikasi Ahok selagi apa yang ia lakukan untuk kepentingan masyarakyat DKI Jakarta.

Namun Ahok mendapatkan nilai terendah pada kemampuan berkomunikasinya. Ia hanya mendapatkan nilai 6,17 dari responden. Dari hasil survey ini pun diketahui bahwa Ahok memiliki sisi kelemahan, yaitu memiliki sifat yang frontal, emosional dan kasar. Terlebih gaya komunikasi Ahok yang frontal, emosional dan kasar ini dibandingbandingkan dengan gaya komunikasi Ali Sadikin yang merupakan Gubernur DKI Jakarta yang menjabat pada 1966 hingga 1977. Kedua pemimpin DKI Jakarta di era yang berbeda ini samasama memiliki ketegasan, keberanian, dan kecerdasan.

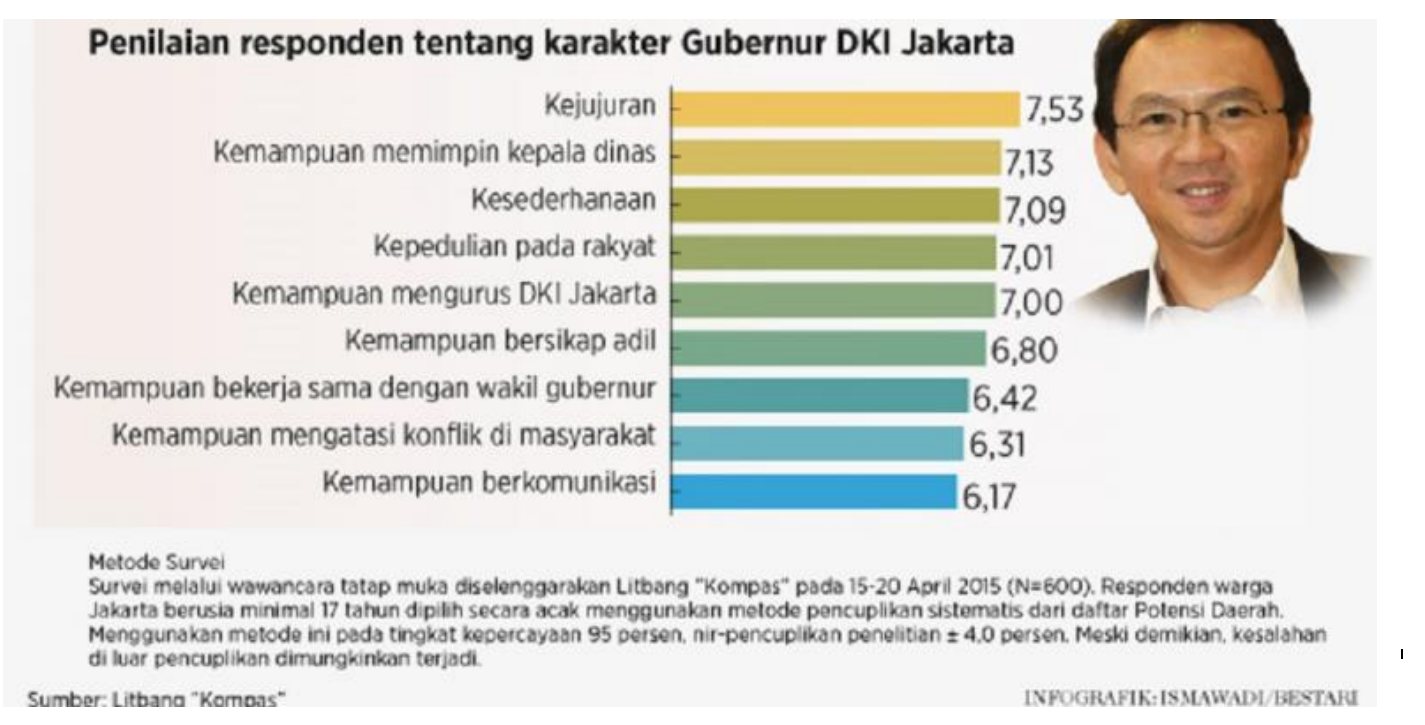

Gambar 1. Penilaian Responden tentang Karakter Gubernur DKI

Sumber: Kompas.com 
Gaya bicara Ahok yang keras, bernada tinggi dan blak-blakan cukup dilematis jika kita menengok pada masyarakat DKI Jakarta yang berasal dari beragam suku dan etnis. Prasetyo (2014) menemukan bahwa dalam memandang sosok Ahok sebagai seorang pemimpin, masyakarat DKI Jakarta tidak mempersoalkan perbedaan latar belakang budaya ataupun agama. Masyarakat menganggap bahwa gaya komunikasi Ahok membawa suasana baru dalam ranah perpolitikan Indonesia khususnya DKI Jakarta dengan memanfaatkan media dalam komunikasi politiknya. Gaya komunikasi Ahok yang tegas dan mengendalikan ternyata juga disetujui oleh masyarakat DKI Jakarta. Namun demikian, metode bicara Ahok yang keras, bernada tinggi dan blak-blakan ketika menyampaikan kebijakan perlu mendapat perhatian khusus mengingat masyarakat DKI Jakarta yang heterogen.

Tidak berbeda jauh dengan apa yang ditemukan oleh Saeni (2017) pada penelitiannya mengenai gaya komunikasi Ahok dari sudut pandang anggota DPR RI DKI Jakarta. Secara umum, hasil penelitiannya menemukan bahwa dalam menyikapi gaya komunikasi Ahok, anggota DPR RI DKI Jakarta terbagi menjadi dua kubu. Kubu pertama merasa bahwa mereka merasa nyaman dan tidak masalah dengan gaya komunikasi yang dimiliki
Ahok. Bahkan mereka mengakui bahwa dibalik gaya komunikasi Ahok yang fenomenal itu terdapat hal positif. Mereka beranggapan bahwa gaya komunikasi yang diterapkan Ahok sudah tepat diterapkan untuk mengelola Provinsi DKI Jakarta dengan beragamnya permasalahan yang terjadi. Mereka menganggap bahwa gaya komunikasi Ahok bagus diterapkan untuk menghadapi koruptor di lingkungan DKI Jakarta.

Berbeda dengan kubu kedua yang mengakui bahwa mereka tidak merasa nyaman, bahkan cenderung tersinggung dengan gaya komunikasi Ahok. Selama berinteraksi dengan Ahok mereka merasa terganggu dengan gaya komunikasi Ahok yang demikian. Mereka menganggap bahwa gaya komunikasi yang diterapkan Ahok tak layak dimiliki dan diterapkan oleh seorang pejabat. Mereka mengakui tidak menemukan sisi positif dalam gaya komunikasi yang diterapkan Ahok.

\section{HASIL DAN PEMBAHASAN}

Blake dan Haroldsen pada bukunya Taxonomy of concepts in communication sebagaimana dikutip dari Zen (2004) menyatakan bahwa komunikasi politik adalah komunikasi yang berengaruh secara aktual dan potensial tentang fungsi dari pernyataan politik atau entitas politik lainnya. Dari definisi tersebut di atas dapat kita simpulkan bahwa melalui 
komunikasi politik kita dapat melihat pernyataan politik dari seorang politikus serta fungsi dan dampaknya. Terlebih di era media saat ini, kita dapat melihat pernyataan politik seorang politikus dengan mudah baik melalui saluran media massa maupun internet, yaitu media sosial. Hal ini disebabkan karena selain komunikator dan isi pesan, media massa merupakan salah satu saluran komunikasi yang paling penting.

Dikutip dari Subiakto et.al (2012), Daniel Katz membedakan politikus menjadi dua jenis, yaitu partisan dan ideolog. Berdasarkan pembagian dua jenis politikus tersebut, Ahok adalah seorang partisan sekaligus seorang ideolog. Sebagai wakil rakyat, Ahok beberapa kali terbukti melindungi dan mengutamakan kepentingan rakyatnya. Namun Ahok juga merupakan seorang ideolog. Ahok seringkali mengeluarkan kebijakankebijakan yang kontroversial untuk sebagian masyarakat dengan dalil-dalil yang ia miliki serta pemahaman materi mengenai kebijakannya tersebut sehingga orang lain pun mengikuti kebijakan tersebut.

Gaya komunikasi (communication style) merupakan sifat antarpribadi yang secara khusus ditampilkan seseorang dalam kondisi tertentu. Gaya komunikasi merupakan metode penyampaian dan gaya bahasa seseorang yang disampaikan dengan baik. Widjaja (2000) menyatakan bahwa gaya yang dimaksud baik verbal yang berupa kata-kata ataupun nonverbal yang berupa intonasi suara, bahasa tubuh, penggunaan waktu, ruang dan jarak.

Mulyana (1996) menyatakan bahwa budaya menjadi salah satu faktor yang mempengaruhi cara orang berbicara. Jika kita telaah dari sisi budaya kita telah ketahui bahwa Ahok merupakan seorang etnis Tionghoa yang lahir dan besar di kepulauan Bangka Belitung. Sifat dan karakter masyarakat yang berasal dari kepulauan Bangka Belitung memang cenderung keras jika dibandingkan dengan masyarakat dari etnis Jawa sebagai etnis mayoritas di Indonesia.

Liliweri (2007) menjelaskan bahwa terdapat dua jenis konteks komunikasi dalam memproses informasi, yaitu Komunikasi Konteks Tinggi dan Komunikasi Konteks Rendah. Komunikasi Konteks Tinggi atau High Context Culture (HHC) merupakan sebuah kebudayaan yang memiliki suatu prosedur pengalihan informasi menjadi sulit untuk dikomunikasikan. Sedangkan Komunikasi Konteks Rendah atau Low Context Culture (LCC) adalah kebudayaan yang prosedur pengalihan informasinya menjadi lebih mudah untuk dikomunikasikan.

Gaya komunikasi yang dimiliki Ahok, memang paling unik dan terkesan ekstrim jika dibandingkan dengan pejabat dan elit politik Indonesia. Apabila kita tarik benang merah antara daerah asal Ahok dan 
gaya komunikasi yang ditampilkan Ahok, maka berdasarkan perspektif lintas budaya diketahui bahwa Ahok menggunakan gaya komunikasi low context atau konteks rendah yang mana gaya komunikasi ini cenderung spontan dan blak-blakan. Ahok lebih suka menggunakan bahasa yang sederhana, bukan bahasa elit yang sering ditampilkan oleh pejabat dan elit politik Indonesia, khususnya DKI Jakarta. Ahok cenderung menggunakan bahasa yang normatif.

\section{Tabel 1}

Komunikasi Konteks Rendah dalam Gaya Kepemimpinan Ahok

\begin{tabular}{|c|c|}
\hline $\begin{array}{c}\text { Komunikasi Konteks Rendah dalam } \\
\text { Gaya Kepemimpinan Ahok }\end{array}$ & Konteks Komunikasi \\
\hline $\begin{array}{l}\text { Memisahkan isu dan orang yang } \\
\text { mengkomunikasikan isu }\end{array}$ & $\begin{array}{lcr}\text { Mempersilahkan } & \text { wartawan } & \text { yang } \\
\text { sebelumnya ia } & \text { marahi } & \text { untuk } \\
\text { mewawancarainya } & \text { pada keesokan } \\
\text { harinya } & & \end{array}$ \\
\hline Kurang memperhatikan sistem nilai & "bego" \\
\hline $\begin{array}{l}\text { Mengutamakan informasi secara } \\
\text { verbal dengan non verbal }\end{array}$ & $\begin{array}{l}\text { Menyukai berbicara dengan } \\
\text { menggunakan nada yang tinggi dibarengi } \\
\text { dengan mata melotot dan telunjuk yang } \\
\text { menuding }\end{array}$ \\
\hline $\begin{array}{l}\text { Tidak suka basa-basi dan cenderung } \\
\text { lugas dalam berkomunikasi }\end{array}$ & "gue ngga mau tau". \\
\hline
\end{tabular}

Jika dibandingkan dengan individu yang berasal dari kebudayaan HHC yang sungkan dalam mengalihkan suatu informasi, individu yang berasal dari kebudayaan LCC cenderung gampang dalam melakukan pengalihan suatu informasi. Individu dari kebudayaan LCC merupakan individu yang eksplisit, to the point, dan blak-blakan serta kurang memperhatikan sistem nilai, norma dan kepercayaan. Mereka mengharapkan lawan bicara memberikan informasi secara garis besar saja karena mereka dapat mengaksesnya dengan mudah. Ahok dalam menyampaikan pesan politiknya cenderung eksplisit, to the point dan blak-blakan. Ahok kurang memperhatikan sistem nilai, jika ia anggap suatu hal yang dilakukan orang salah maka ia akan langsung mengatakannya tanpa memperdulikan bahwa yang diungkapkannya itu bertolak belakang dengan nilai-nilai yang dianut masyarakat. Ahok melalui gaya bicaranya yang cenderung eksplisit, to the point dan blak-blakan mengharapkan agar lawan bicaranya memberikan informasi yang tidak bertele-tele sehingga ia dapat mengakses informasi yang diberikan lawan bicaranya itu dengan mudah. Ahok pun berharap agar lawan bicaranya juga menyampaikan informasi yang lebih sederhana agar 
dapat dengan cepat dipahami olehnya dalam berbagai situasi dan kondisi.

Individu dari kebudayaan HCC juga berharap agar lawan bicaranya menggunakan cara yang lebih simpel agar mereka dapat langsung memahami segala bentuk informasi dalam berbagai kondisi. Akan tetapi apabila kita kaji dengan menggunakan perspektif komunikasi lintas budaya, apa yang ditampilkan Ahok dengan gaya bahasanya yang non-formal dan cenderung kasar sangat bertolak belakang dengan karakteristik LCC, yaitu mengutamakan suasana informasi yang formal.

Nurkamto (2001) menyatakan bahwa, seperti bangsa Asia lainnya, Indonesia merupakan negara yang mayoritas penduduknya memiliki gaya komunikasi konteks tinggi (HCC). Sejalan dengan itu, maka gaya bahasa dan komunikasi yang ditampilkan pejabat dan elit politik Indonesia umumnya adalah HCC. Pada umumnya, gaya bahasa pejabat dan elit politik di Indonesia dapat digolongkan menjadi empat jenis, yaitu gaya pengingkaran terhadap kenyataan, gaya eufemistik, samar-samar dan berputarputar. Keempat jenis gaya bahasa pejabat dan elit politik Indonesia sangat kontras jika dibandingkan dengan gaya komunikasi Ahok. Misalnya gaya berputar-putar. Gaya ini merupakan gaya bahasa yang cenderung berteletele dan tidak langsung menjurus pada pokok persoalan. Gaya ini khas dimiliki oleh mayoritas pejabat
Indonesia. Masyarakat kita pun telah terbiasa dengan gaya semacam ini dan menganggapnya sebagai suatu hal yang lumrah. Gaya ini sangat kontras dengan gaya komunikasi yang dimiliki Ahok.

Saphiere, et al (2005) menjelaskan bahwa tiap individu memiliki gaya komunikasi yang berbeda-beda. Ia menambahkan bahwa gaya komunikasi merupakan gambaran dari karakter pribadi individu tersebut. Berdasarkan penjelasan tersebut dapat kita simpulkan bahwa bukan suatu hal yang mengherankan jika Ahok memiliki gaya komunikasi yang berbeda dari kebanyakan pejabat atau elit politik di Indonesia. Ahok sendiri sebagai seorang individu memiliki karakter yang relatif sama dengan gaya kemepimpinannya yang ia tampilkan selama ini, yaitu to the point dan blakblakan.

Saphiere, et al (2005) juga menambahkan bahwa terdapat beberapa faktor yang berandil besar dalam gaya komunikasi seseorang, diantaranya adalah konteks komunikasi, tujuan komunikasi, konsep diri individu, nilai-nilai yang dianut oleh individu, dan gaya komunikasi yang diterapkan oleh individu ketika berinteraksi.

Selayaknya budaya, gaya komunikasi merupakan suatu hal yang relatif, dinamis dan sukar ditebak. Namun gaya komunikasi yang ditampilkan Ahok relatif sama. Secara verbal, orang dari budaya berbeda akan menganggap kata-kata yang diucapkan 
Ahok cenderung kasar, meledak-ledak dan tegas. Secara nonverbal intonasi suara yang dimiliki Ahok sangat tinggi. Konteks dan konten pembicaraannya pun masih terbilang normal dan wajar jika kita menengok dengan kaca mata komunikasi konteks rendah (LCC). Namun ternyata tanggapan dari masyarakat mengenai pidato sambutan Ahok ini menjadi beragam. Terlebih jika melihatnya dengan menggunakan komunikasi konteks tinggi (HCC). Orang dengan budaya konteks tinggi akan menganggap apa yang disampaikan Ahok terkesan arogan, sombong, hingga menistakan agama. Jadi, sebenarnya permasalahan kasus penistaan agama yang mendera Ahok bukan hanya dapat ditelaah dalam konteks kajian politik dan bahasa saja, tapi juga dapat dilihat dari konteks budaya, baik itu budaya yang dimiliki Ahok maupun budaya masyarakat yang melihat pidato Ahok tersebut.

Sesungguhnya gaya komunikasi yang dimiliki Ahok tersebut mempunyai kekuatan dan kelemahan untuk Ahok. Kekuatannya adalah bahwa gaya komunikasi yang ditampilkan Ahok berkenaan dengan program-program politiknya dapat dengan mudah dimengerti oleh semua kalangan masyarakat. Ahok menggunakan bahasa yang lugas, spontan dan sederhana. Gaya komunikasi Ahok yang keras dan tegas cocok untuk mengelola DKI Jakarta yang memiliki permasalahan yang cukup kompleks, diantaranya memberantas tindakan korupsi yang terjadi dalam ruang lingkup Provinsi DKI Jakarta.

Ahok bagi sebagian masyarakat memiliki sisi kejujuran yang tinggi, berani dan sederhana jika dibandingkan dengan Gubernur DKI Jakarta lainnya. Berdasarkan poin-poin tersebut dapat dikatakan bahwa masyarakat tidak terlalu mempermasalahkan gaya komunikasi Ahok selagi apa yang ia lakukan untuk kepentingan masyarakyat DKI Jakarta. Akan tetapi gaya komunikasi Ahok ini terdapat kelemahannya juga, yaitu bahasa yang lugas dan spontan serta blak-blakan jika sudah melebihi batasan norma masyarakat kita akan menjadi blunder untuk Ahok. Akibat dari ucapan Ahok yang cenderung blak-blakan dan kasar sudah mendapat banyak kritikan dari beberapa kalangan.

Data sensus penduduk tahun 2000 mencatat jumlah penduduk DKI Jakarta sebanyak 8,3 juta jiwa. Etnis terbanyak adalah etnis Jawa dengan jumlah 35,16\%, disusul etnis Betawi $(27,65 \%)$,

Sunda $(15,27 \%)$, Tionghoa $(5,53 \%)$, B atak $(3,61 \%)$, Minangkabau $(3,18 \%)$, Melayu $(1,62 \%)$. Berdasarkan data tersebut dapat disimpulkan bahwa sebagian masyarakat DKI Jakarta menganut komunikasi konteks tinggi atau HCC. Orang-orang dari kebudayaan HCC berharap supaya lawan bicaranya menggunakan metode yang lebih simpel agar mereka dapat langsung memahami segala bentuk 
informasi dalam berbagai kondisi. Orang yang menganut HCC merupakan individu yang implisit, dan lebih memperhatikan sistem nilai, norma dan kepercayaan. Karakteristik masyarakat DKI yang mayoritas menggunakan komunikasi HCC berbading terbalik dengan karakter Ahok yang menganut komunikasi LCC. Perbedaan ini sebenarnya dapat mengakibatkan terjadinya kesalahpahaman yang pada tataran selanjutnya berpotensi konflik.

Astriningsih

(2011)

menyatakan bahwa agar kesalahpahaman dapat dihindari, masyarakat harus memiliki sikap saling terbuka dan berusaha untuk memahami pihak lain. Pada konteks ini, masyarakat DKI Jakarta hendaknya memiliki sikap terbuka dan memahami karakteristik Ahok yang blak-blakan dan cenderung frontal dan temperamental. Ahok pun demikian, hendaknya memahami karakteristik masyarakatnya agar pesan politiknya dapat tersampaikan dengan baik kepada masyarakat.

\section{SIMPULAN}

Gaya komunikasi yang dimiliki Ahok, memang paling unik dan terkesan ekstrim jika dibandingkan dengan pejabat atau elit politik Indonesia pada umumnya. Ahok menggunakan gaya komunikasi low context atau konteks rendah yang mana gaya komunikasi ini cenderung spontan dan blak-blakan. Ahok lebih suka menggunakan bahasa yang sederhana, bukan bahasa elit yang sering ditampilkan oleh pejabat atau elit politik Indonesia pada umumnya. Sesuai dengan karakteristik Low Context Culture (LCC) bahwa Ahok dalam menyampaikan pesan politiknya cenderung eksplisit, to the point dan blak-blakan. Ahok kurang memperhatikan sistem nilai, jika ia anggap suatu hal yang dilakukan orang salah maka ia akan langsung mengatakannya tanpa memerdulikan bahwa yang diungkapkannya itu bertolak belakang dengan nilai-nilai yang dianut masyarakat. Namun terdapat beberapa gaya komunikasi Ahok yang tidak berkesesuaian dengan karakteristik LCC, yaitu ketika berbicara Ahok cenderung menggunakan bahasa non formal dengan intonasi suara yang tinggi.

Gaya komunikasi Ahok yang menerapkan komunikasi konteks rendah (LCC) ini cukup ideal untuk diterapkan oleh seorang pemimpin, terlebih memimpin Provinsi DKI Jakarta yang memiliki masalah yang beragam dengan masyarakat dari suku dan etnis yang beragam pula. Walau memang tidak berkesuaian dengan gaya komunikasi pemimpin pada umumnya yang menerapkan gaya komunikasi konteks tinggi (HCC), gaya komunikasi Ahok dapat menjadi penangkal untuk para koruptor agar mereka enggan dipermalukan di depan umum oleh Ahok jika terbukti melakukan tindakan korupsi. 


\section{UCAPAN TERIMA KASIH}

Penulis

mengucapkan

terimakasih kepada pihak-pihak yang telah membantu dalam penyelesaian penulisan tulisan ini. Terimakasih diucapkan untuk keluargaku tercinta, khususnya kepada suamiku atas semua support yang diberikan. Terimakasih juga diucapkan kepada Melkoters atas support yang diberikan kepada penulis. Tentunya tulisan ini masih jauh dari sempurna. Oleh sebab itu penulis sangat membutuhkan masukan yang membangun dari pembaca semua. Semoga tulisan ini bermanfaat.

\section{Daftar Pustaka}

Buku:

Liliweri, A. (2003). Dasar-dasar Komunikasi Antarbudaya. Yogyakarta: Pustaka Pelajar.

$\begin{array}{lr}\text { Dalam } & \text { Komunikasi } \\ \text { Antarbudaya. } & \text { Yogyakarta: } \\ \text { LkiS. } & \end{array}$

Mulyana, D. dan Jalluddin R. (1996). Komunikasi Antarbudaya Panduan Berkomunikasi dengan Orang-Orang Berbeda Budaya. Bandung: Remadja Rosda Karya.

Porter, R.E., et.al. (1996). "Suatu Pendekatan Terhadap Komunikasi Antarbudaya." Dalam Mulyana dan Rachmat (ed), Komunikasi Antarbudaya: Panduan Berkomunikasi dengan Orang-Orang Berbeda
Budaya. Bandung: Remaja Rosdakarya.

Saphiere, D.H., Babara K. M., dan Basma I. D. (2005). Communication highwire: leveraging the power of diverse communication styles. Boston: Intercultural Press.

Subiakto, Henri \& Ida, Rachmah. (2012). Komunikasi Politik, Media dan Demokrasi. Edisi Pertama. Jakarta: Kencana Prenada Media Group. Widjaja, H.A.W. (2000). Ilmu Komunikasi Pengantar Studi. Jakarta: PT. Rineka Cipta.

Zen, F. (2004). NU Politik Analisis Wacana Media. Yogyakarta: LKiS.

\section{Sumber lain:}

Astriningsih, R. (2011). Memahami Gaya Konflik Budaya Konteks Tinggi dan Rendah Dalam Konflik Kesalahpahaman Hubungan Pertemanan (Friendly Relationship). Skripsi. Universitas Diponegoro. Semarang.

Junaidi. (2006). Komunikasi dan Budaya: Menuju Masyarakat Multikultural. Jurnal Ilmu Budaya. Vol. 3, No. 1 Tahun 2006: 1-65.

Kistyarini. (2015, Mei 27). "Gubernur DKI, antara Retorika dan Sosok". Kompas.com. Diakses dari https://megapolitan.kompa $\underline{\text { s.com } / \mathrm{read} / 2015 / 05 / 27 / 150600}$ 
61/Gubernur.DKI.antara.Retori ka.dan.Sosok.

Muksin, N.N. (2017). Kredibilitas

Komunikator Politik Basuki

Tjahaya Purnama "Ahok"

sebagai Gubernur Provinsi

DKI Jakarta. Jurnal Perspektif

Komunikasi UMJ. Vol. 1 No. 2

Juli - Desember 2017.

Nurkamto, J. (2001). "Berbahasa dalam Budaya Konteks Rendah dan Budaya Konteks Tinggi" dalam Linguistik Indonesia. Jurnal Ilmiah Masayarakat linguistik Indonesia. No.2. Agustus 2001.

Prasetyo, D. (2014). Persepsi Masyakarat Dki Jakarta Terhadap Figur dan Komunikasi Politik Basuki Tjahaja Purnama (Ahok). Politika, Vol. 5, No.2, Oktober 2014.

Rahmah, M. (2018). Gaya komunikasi pemimpin di media (Analisis Semiotika Gaya Komunikasi Basuki Tjahaja Purnama "Ahok" dalam Tayangan Mata Najwa On Stage "Semua Karena Ahok" Di Metro TV). Skripsi. Universitas Sumatera Utara Fakultas Ilmu Sosial dan Ilmu Politik Departemen Ilmu Komunikasi. Medan.

Rani, N.L.M.R. (2014). Preferensi Opini Publik dalam Media Online (Preferensi Opini Publik terhadap Citra Ahok dalam Lipsus Kompas.com tentang
Penertiban PKL Pasar Tanah Abang Bulan Juli 2013). Tesis. Universitas Gadjah Mada. Yogyakarta.

Saeni, E. (2017). Pengalaman Anggota DPRD DKI Jakarta dalam Berkomunikasi Politik dengan Gubernur DKI Jakarta Basuki Tjahaja Purnama (Ahok) (Studi Fenomenologi Terhadap 17 Anggota Dprd Dki Jakarta Periode 2014-2017). Artikel Ilmiah. Program Pascasarjana Universitas Pasundan Program Magister Ilmu Komunikasi. Bandung.

Jessica Carina. (2016, November 02). Membandingkan Gaya Komunikasi Agus, Ahok, dan Anies. Kompas.com. Diakses dari

https://megapolitan.kompas.co $\underline{\mathrm{m} / \mathrm{read} / 2016 / 11 / 02 / 08062401 /}$ membandingkan.gaya.komunik asi.agus.ahok.dan.anies.

Johnson Simanjuntak. (2016, Oktober 06). Gaya Komunikasi Ahok Menjadi Salah Satu Faktor Menurunnya Elektabilitas. Tribunnews.com. Diakses dari http://www.tribunnews.com/na sional/2016/10/06/gayakomunikasi-ahok-menjadisalah-satu-faktor-menurunnyaelektabilitas.

Dewanto Samodro. (2016, September 29). Gaya Komunikasi Ahok Jadi Kelemahan. 
Antaranews.com. Diakses dari http://www.antaranews.com/be rita/587264/gaya-komunikasiahok-jadi-kelemahan.

Untung Pramono. (2015, Juni 16). Survei Periskop Data: Kinerja Ahok Baik, Tetapi Komunikasi Buruk. Merdeka.com. Diakses dari

https://www.merdeka.com/jaka $\underline{\text { rta/survei-periskop-data- }}$ kinerja-ahok-baik-tetapikomunikasi-buruk.html.

Ana Shofiana Syatiri. (2017, April 20). Pilkada DKI 2017 dalam Berita Terpopuler Kompas.com. Kompas.com. Diakses dari https://megapolitan.kompas.co $\underline{\mathrm{m} / \mathrm{read} / 2017 / 04 / 20 / 08245041 /}$ pilkada.dki.2017.dalam.berita.t erpopuler.kompas.com 